\title{
Intratumoural spatial distribution of S100B + folliculostellate cells is associated with proliferation and expression of FSH and ERa in gonadotroph tumours
}

\author{
Mirela Diana Ilie ${ }^{1,2}$, Alexandre Vasiljevic ${ }^{1,3}$, Marie Chanal ', Nicolas Gadot ${ }^{1,4}$, Laura Chinezu ${ }^{5,6}$, \\ Emmanuel Jouanneau ${ }^{1,7}$, Ana Hennino ${ }^{1}$, Gérald Raverot ${ }^{1,8}$ and Philippe Bertolino ${ }^{1 *}$ (D)
}

\begin{abstract}
Folliculostellate cells are S100B-expressing cells with numerous functions in the normal anterior pituitary. These cells have also been identified in pituitary neuroendocrine tumours (PitNETs), where their precise role remains elusive. Here, we aimed to build a refined cartography of S100B-expressing cells to characterise their interpatient and intratumoural spatial distribution, and to start identifying their potential functions in PitNETs. High-throughput histological analysis of S100B-stained tumour sections of 54 PitNETs revealed a significant decrease in S100B + cells in PitNETs compared to the normal anterior pituitary. A Ki67 index $\geq 3$, a mitosis count $>2 / 10$ per high power fields, and a proliferative status, were all associated with fewer S100B + cells in gonadotroph tumours. Gonadotroph tumours also showed interpatient and intratumoural heterogeneity in the spatial distribution of S100B + cells. The existence of an intratumoural heterogeneity was further confirmed by the incorporation to our spatial analysis of additional markers: Ki67, FSH, LH, ERa and SSTR2. The tumour areas with fewer S100B + cells displayed a higher percentage of Ki67 + cells, whereas strong positive correlations were observed between S100B + , FSH +, and ERa + cells. Such spatial associations suggest that $\mathrm{S100B}+$ folliculostellate cells could play a role in gonadotroph tumorigenesis, and may contribute to the maintenance of tumour cells in a low proliferating, FSH + /ERa + differentiated state. Albeit, further in-depth functional studies are required to decipher the mechanisms underlying these spatial associations and to potentially identify a therapeutic use.
\end{abstract}

Keywords: Tumour heterogeneity, Folliculostellate cells, S100B + cells, Tumour microenvironment, Gonadotroph adenoma

\section{Introduction}

Pituitary neuroendocrine tumours (PitNETs) are the second most common adult intracranial tumours. They account for around 15\% of intracranial neoplasms and represent a major health issue with a prevalence of 1 in

*Correspondence: philippe.bertolino@inserm.fr

${ }^{1}$ Inserm U1052, CNRS UMR5286, University Claude Bernard Lyon 1 Cancer Research Center of Lyon, Lyon, France

Full list of author information is available at the end of the article
1000 people [1-3]. Their diagnosis and the prediction of their behaviour are challenging due to differences in their cell-of-origin within the anterior pituitary gland (APG) (gonadotroph, corticotroph, and cells of the Pit1 lineage, namely somatotroph, lactotroph, and thyrotroph cells) and their secretory capacity (functioning or non-functioning lesions). Though patients suffering from Pit 1 and corticotroph tumours have benefited from the development of effective therapeutic options, gonadotroph tumours, which originate from original author(s) and the source, provide a link to the Creative Commons licence, and indicate if changes were made. The images or other third party material in this article are included in the article's Creative Commons licence, unless indicated otherwise in a credit line to the material. If material is not included in the article's Creative Commons licence and your intended use is not permitted by statutory regulation or exceeds the permitted use, you will need to obtain permission directly from the copyright holder. To view a copy of this licence, visit http://creativecommons.org/licenses/by/4.0/. The Creative Commons Public Domain Dedication waiver (http://creativeco mmons.org/publicdomain/zero/1.0/) applies to the data made available in this article, unless otherwise stated in a credit line to the data. 
follicle-stimulating hormone (FSH)- and luteinizing hormone (LH)-producing cells, and account for up to $35 \%$ of all PitNETs $[4,5]$, currently lack effective medical treatments [6]. In addition, gonadotroph tumours may present multiple recurrences with an unpredicted time-course following their surgical resection (relapse at 5 years being seen in $10-40 \%$ of patients) [7, 8]. Moreover, a small percentage of PitNETs displays an aggressive behaviour that remains difficult to predict $[9$, $10]$, characterised by resistance and/or multiple recurrences despite multimodal treatments $[9,11]$. Therefore, the identification of factors associated with and/or leading to an aggressive phenotype, as well as the identification of new therapeutic targets and novel treatment options are of particular importance.

The tumour microenvironment (TME) that includes blood and lymph vessels, immune cells, cancer-associated fibroblasts, as well as extracellular matrix components, and soluble molecules [12], represents an appealing prognostic tool and a therapeutic target, and has been extensively described in numerous cancers [13]. However, the knowledge on the TME of PitNETs is still limited [14, 15]. Folliculostellate (FS) cells are non-endocrine APGresident cells, identified based on their morphology and immunoreactivity to the S100B protein $[16,17]$. FS cells account for $\sim 5 \%$ of the normal APG $[18,19]$, where they have numerous roles, including a supportive role [20], the regulation of hormone secretion [18], phagocytic properties [21], and the production of numerous cytokines and growth factors such as interleukin 6 (IL-6), follistatin, basic fibroblast growth factor, transforming growth factor $\beta$, and vascular endothelial growth factor [22]. FS cells were also described in PitNETs [23-25], suggesting they might play a role in these tumours. However, their function on tumorigenesis-related processes and their usefulness as a biomarker or as a therapeutic target remain underexplored.

Here, we assessed the presence and distribution of S100B + cells within the TME of PitNETs in order to provide a refined cartography of $\mathrm{S} 100 \mathrm{~B}+$ cells within tumours and between patients. We developed a highthroughput pipeline of single-cell histological analysis based on whole tumour serial sections obtained from a series of 54 surgically-resected PitNETs. We uncover an interpatient and an intratumoural heterogenous distribution of S100B + cells in gonadotroph tumours. In addition, our findings highlight the spatial relationships between the presence of FS cells and the proliferative capacity, as well as FSH and oestrogen receptor alpha $(E R \alpha)$ immunoreactivity of gonadotroph tumour cells, suggesting potential roles of $\mathrm{S} 100 \mathrm{~B}+$ cells in gonadotroph tumorigenesis.

\section{Material and methods}

Tumour and normal APG samples

All pituitary tumours $(n=54)$ were collected by the same surgeon (E.J.), and subsequently diagnosed in the Pathology Department of Groupement Hospitalier Est, Hospices Civils de Lyon, Lyon, France by a single pathologist (A.V.). Normal APG samples $(\mathrm{n}=4)$ used as controls were obtained from the Pathology Department of Targu Mures Emergency Hospital, Targu Mures, Romania. These were collected during autopsies performed at 6-20 h after death on adult patients who have died suddenly, without prior known endocrine dysfunction. Those patients did not have traumatic head injury, documented prolonged multiple organ failure or cerebral ischemia prior to death, and they did not have evident signs of cerebral autolysis or incidental sellar/parasellar lesions.

\section{Clinicopathological data}

S100B immunostaining was prospectively incorporated in the histopathological and immunohistochemistry (IHC) diagnostic routines. Clinicopathological data were collected from the medical files of patients included. The IHC diagnosis of different PitNET subtypes was based on hormone immunoreactivity: FSH, LH, prolactin, growth hormone, thyroid-stimulating hormone, and adrenocorticotropic hormone. When no hormone expression was identified, IHC for transcription factors (steroidogenic factor 1 (SF1), pituitary specific transcription factor (Pit1), and T-box transcription factor TBX19 (T-pit)), completed the diagnosis $[26,27]$. For statistical analysis, tumours of the Pit1 lineage were considered together. Tumours were classified as functioning or non-functioning based on FSH, $\mathrm{LH}$, and sex hormone levels; prolactin levels; growth hormone levels during the glucose tolerance test and insulin-like growth factor 1; thyroid-stimulating hormone and free thyroxine levels; free urinary cortisol, the response to dexamethasone suppression tests, and adrenocorticotropic hormone levels. Tumours were classified as proliferative (i.e., "proliferative status") when at least two of three criteria of proliferation, namely Ki67 index $\geq 3 \%$, mitoses $n>2 / 10$ high power fields (HPFs) $(400 \times$ magnification), and positive p53 ( $>10$ strongly positive nuclei/10 HPFs), were present [28]. Invasion was defined as cavernous and/or sphenoid sinus invasion detected on magnetic resonance imaging and/or during surgery; for the cavernous sinus invasion detected on magnetic resonance imaging, the revised Knosp classification was used [29]. The grading of tumours was based on the published five-tiered clinicopathological classification (1a, non-invasive and non-proliferative; $1 \mathrm{~b}$, non-invasive, but proliferative; $2 \mathrm{a}$, invasive, but not proliferative; and $2 \mathrm{~b}$, invasive and proliferative; 3 , metastatic tumour) [28]. 


\section{Immunohistological staining}

For IHC, staining was conducted on $4 \mu \mathrm{m}$ serial sections obtained from formalin-fixed paraffin-embedded (FFPE) tissues through a routine protocol performed on a BenchMark ${ }^{\circledR}$ ULTRA immunostainer (Ventana Medical Systems Inc, Roche Diagnostics, Tucson, Arizona, USA). Detection of positive staining was done using diaminobenzidine (ultraView Universal DAB Detection Kit, Ventana Medical Systems Inc, Tucson, Arizona, USA) followed by haematoxylin counterstaining (Bluing Reagent, Ventana Medical Systems Inc, Roche Diagnostics, Tucson, Arizona, USA). Primary antibodies for IHC were as follow: S100B (Agilent Dako, \#Z0311), FSH (Beckman Coulter Immunotech, \#0373), LH (Agilent Dako, \#M3502), Ki67 (Agilent Dako, \#M7240), ER $\alpha$ (clone SP1, Ventana Medical Systems Inc.), and somatostatin receptor type 2 (SSTR2) (Abcam, \#ab134152). For immunofluorescence (IF), staining was performed using standard protocols. Briefly, $4 \mu \mathrm{m}$-thick FFPE sections were first deparaffinised at $55{ }^{\circ} \mathrm{C}$ for 30 min prior to 5 min of incubation in xylene. Tissue sections were subsequently rehydrated in decreasing concentrations of ethanol (100\%, 95\% and 70\%). Heat-induced epitope retrieval was performed using a citrate-based unmasking solution at pH 6.0 (Vector Laboratories, California, USA, \#H-3300) prior to a $1 \mathrm{~h}$ blocking step and an overnight incubation with S100B (Abcam, \#ab52642) and FSH (Beckman Coulter Immunotech, \#0373) primary antibodies. Secondary antibodies coupled to fluorochromes (anti-mouse-AlexaFluor488, cat\#712-546-151, and antirabbit-Cy3, cat\#711-166-152, Jackson ImmunoResearch, UK) were then incubated for $30 \mathrm{~min}$ before mounting the sections with a DAPI counterstaining solution (Vector Laboratories, California, USA, \#H-1200).

\section{Slide scanning and image analysis}

Stained whole sections were scanned at $20 \times$ using a Pannoramic Scan (3D HISTECH Ltd., Budapest, Hungary) or a Zeiss Axio Scan.Z1 (Carl Zeiss Microscopy GmbH, Jena, Germany). Scanned images were visualised with CaseViewer software (3D HISTECH Ltd., Budapest, Hungary) and Zen2 software (blue edition). Image analysis, subsequent segmentation, and staining quantification, were performed with $\mathrm{HALO}^{\circledR}$ software v.2.3.2089.27 (Indica Labs, New Mexico, USA). Our pathologist (A.V.) manually annotated the areas corresponding to tumour tissue and to adjacent APG tissue (when present). The regions with staining artefacts were excluded prior to performing a single-cell segmentation with $\mathrm{HALO}^{\circledR}$ CytoNuclear module v1.6. Segmentation was then double-checked by eye for each sample to ensure that cells were correctly identified before quantifying the percentage of positive cells out of the total number of cells present within the area analysed. Finally, spatial plots that illustrate each stained cell as an individual point, were generated.

\section{Statistical analysis}

Statistical analysis was performed in $\mathrm{R}$ commander/R package version 3.5.1 (R-project, Vienna, Austria) and GraphPad Prism 5 (GraphPad, California, USA). MannWhitney test, Kruskal-Wallis test followed by Dunn's post-test, Wilcoxon matched paired test, Student's t-test with Welch's correction, and Spearman's correlation were applied as indicated. $p<0.05$ (adjusted $p<0.05$ in case of multiple comparisons) was considered significant. Graphs were generated with GraphPad Prism 5 (GraphPad, California, USA).

\section{Results}

High-throughput histological single-cell analysis based on whole-slide quantification reveals a loss of S100B + cells in PitNETs in comparison to normal APG

Quantification of immunoreactive cells on tissue sections is generally conducted either semi-quantitatively or by quantifying a limited number of selected fields. For the purpose of our study, we deemed such approaches to be imprecise, as the heterogeneous distribution of cells among tissues analysed can be overlooked. Thus, we developed a pipeline of IHC analysis to quantify singlecell staining on whole tumour sections (Fig. 1A). Analysis of FSH and SF1 expression of a gonadotroph tumour confirmed the feasibility of our technical approach, giving us the possibility to quantify and address the spatial distribution of immunoreactive cells in a large number (hundreds of thousands) of cells per section (Fig. 1B, C).

Following this validation, we analysed the number and the spatial distribution of FS cells through their S100B immunoreactivity, in a cohort of 54 patients with PitNETs (26 gonadotroph tumours, 20 tumours of the Pit1 lineage, and 8 corticotroph tumours) and 4 normal APG samples. The clinicopathological characteristics of the tumours analysed are detailed in Table 1. Quantification of S100B + cells on scanned whole-sections (Additional file 1: Fig. S1) confirmed that $\mathrm{S} 100 \mathrm{~B}+$ cells could be detected in normal APG, as well as in gonadotroph, corticotroph, and Pit1 tumours (Fig. 2A). Quantification of S100B + cells at the whole tumour level highlighted that tumour tissue showed a significant decrease in S100B + cells (median 0.18\%) compared to normal APG (median 3.95\%) (Fig. 2B). To refine this observation, we used histological sections in which both tumour and adjacent APG areas were present, and comparatively quantified the percentage of S100B + cells in 
A

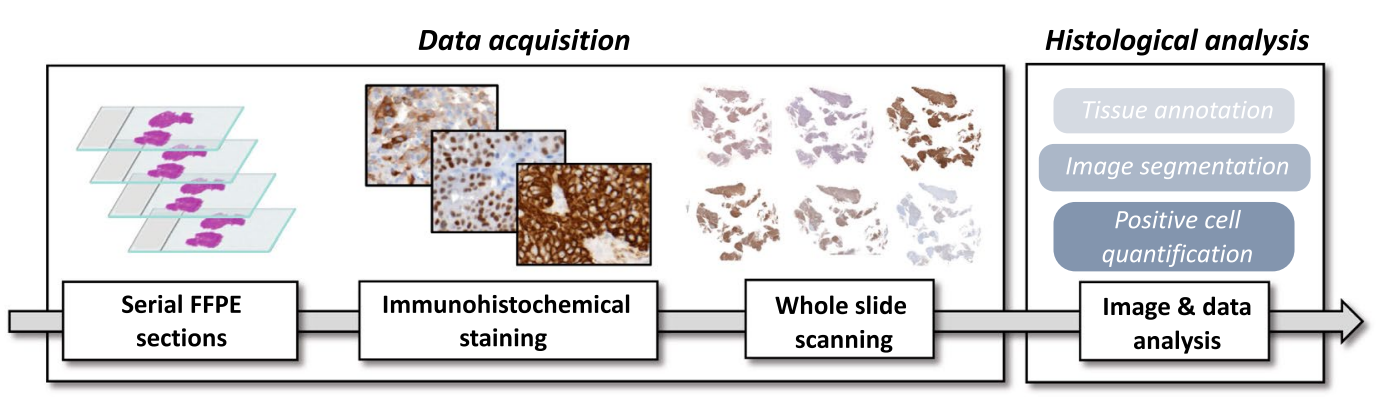

B

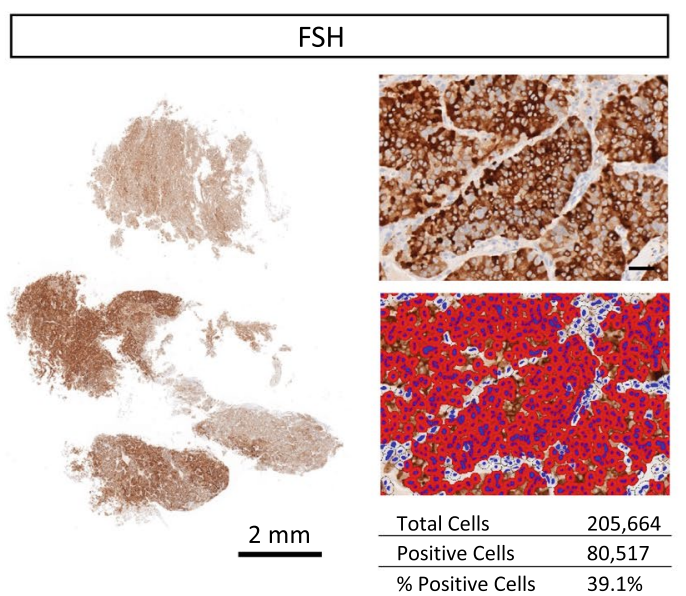

C

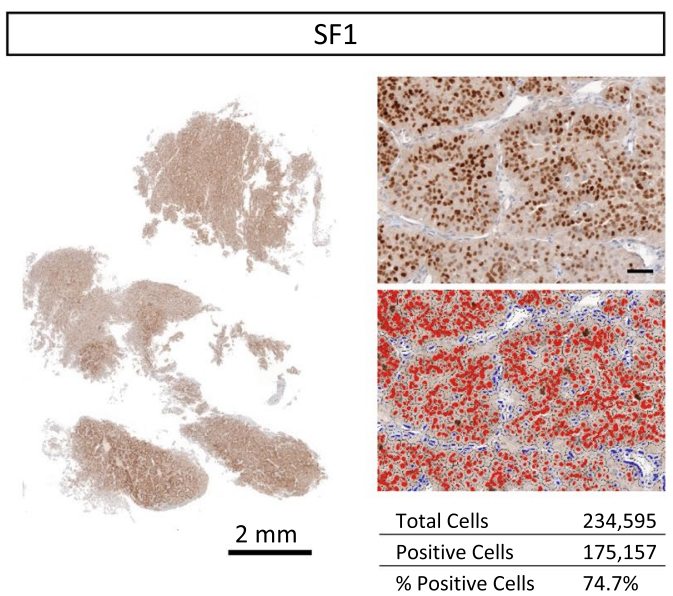

Fig. 1 Schematic overview and representative analyses of our multi-marker histological quantification approach based on scanned whole-slides. A Working flow of our experimental/analysis pipeline. B, C Representative quantification of cytoplasmic (B) and nuclear (C) immunohistochemical staining using single-cell segmentation performed with the HALO ${ }^{\circledR}$ software (Indica Labs, New Mexico, USA) on scanned serial sections. Left panels show whole-section scans of immunohistochemical staining. Right panels are enlarged views of the immunohistochemical staining (top), with the matching image segmentation (bottom). Nuclei are segmented in blue, and positive staining is segmented in red. Quantification results are shown in the tables associated, as follows: total number of cells (counted on the total number of nuclei on the whole scan), number of positive cells, and the percentage of positive cells over the number of total cells. Scale bar of the enlarged images $=50 \mu \mathrm{m}$. Abbreviations: formalin-fixed paraffin-embedded (FFPE), follicle-stimulating hormone (FSH), steroidogenic factor 1 (SF1)

individual patients. As shown in Fig. 2C, this quantification confirmed that the percentage of S100B + cells was lower in the tumour tissue compared to adjacent APG tissue, independently of the PitNET subtype. Interestingly, whereas most of the tumours analysed displayed a very low percentage of S100B + cells ( 43 tumours had $<1 \%$ of S100B + cells and 19 tumours $<0.1 \% \mathrm{~S} 100 \mathrm{~B}+$ cells), a small fraction of them had a higher percentage of S100B + cells reaching a maximum of $9.55 \%$ (Fig. 2B). Taken together, these observations suggest an interpatient heterogeneity regarding the percentage of intratumoral S100B + cells, which, nonetheless, is decreased in the majority of PitNETs in comparison to the normal APG.
The presence of intratumoural $\mathrm{S} 100 \mathrm{~B}+$ cells is associated with lower proliferative properties and positively correlated with ERa expression in gonadotroph tumours We next investigated whether the percentage of intratumoural S100B + cells at the whole tumour level was associated with the clinicopathological characteristics of PitNETs analysed. We found that tumours with a Ki67 index $\geq 3 \%$ were associated with significantly fewer $\mathrm{S} 100 \mathrm{~B}+$ cells $(p=0.01)$ (Fig. 3A), whereas there was no association between the percentage of $\mathrm{S} 100 \mathrm{~B}+$ cells and the tumour invasive trait (Fig. 3B). We then wondered whether these observations were related to specific PitNET subtypes. Although the 
Table 1 Clinicopathological characteristics of the tumours included in the study, considered together and by cell lineage

\begin{tabular}{|c|c|c|c|c|}
\hline & All tumours $n=54$ & Gonadotroph $n=26$ & Pit1 lineage $n=20$ & Corticotroph $n=8$ \\
\hline Age at surgery (years) & $56(27-87)$ & $63(37-87)$ & $49(27-77)$ & $52(33-66)$ \\
\hline \multicolumn{5}{|l|}{ Gender } \\
\hline Female & $32(59 \%)$ & $12(46 \%)$ & $14(70 \%)$ & $6(75 \%)$ \\
\hline Male & $22(41 \%)$ & $14(54 \%)$ & $6(30 \%)$ & $2(25 \%)$ \\
\hline \multicolumn{5}{|l|}{ Sample localization } \\
\hline Tumour tissue & $54(100 \%)$ & $26(100 \%)$ & $20(100 \%)$ & $8(100 \%)$ \\
\hline Adjacent anterior pituitary & $9(17 \%)$ & $2(8 \%)$ & $5(25 \%)$ & $2(25 \%)$ \\
\hline \multirow[t]{2}{*}{ Maximal diameter $(\mathrm{mm})^{*}$} & $24(5-60)$ & $30(20-55)$ & $21(7-60)$ & $15(5-32)$ \\
\hline & $n=45$ & $n=22$ & $n=16$ & $n=7$ \\
\hline \multicolumn{5}{|l|}{ Invasion } \\
\hline Yes & $28(52 \%)$ & $15(58 \%)$ & $9(45 \%)$ & $4(50 \%)$ \\
\hline No & $18(33 \%)$ & $7(27 \%)$ & $9(45 \%)$ & $2(25 \%)$ \\
\hline NA & $8(15 \%)$ & $4(15 \%)$ & $2(10 \%)$ & $2(25 \%)$ \\
\hline \multicolumn{5}{|l|}{ Proliferation } \\
\hline No & $46(85 \%)$ & $23(88 \%)$ & $16(80 \%)$ & $7(88 \%)$ \\
\hline Yes & $8(15 \%)$ & $3(12 \%)$ & $4(20 \%)$ & $1(12 \%)$ \\
\hline \multicolumn{5}{|l|}{ Ki67 index } \\
\hline$<3 \%$ & $43(80 \%)$ & $22(85 \%)$ & $16(80 \%)$ & $5(62 \%)$ \\
\hline$\geq 3 \%$ & $11(20 \%)$ & $4(15 \%)$ & $4(20 \%)$ & $3(38 \%)$ \\
\hline \multicolumn{5}{|l|}{ Mitosis } \\
\hline$\leq 2 / 10 \mathrm{HPFs}$ & $47(87 \%)$ & $22(85 \%)$ & $18(90 \%)$ & $7(88 \%)$ \\
\hline$>2 / 10 \mathrm{HPFs}$ & $7(13 \%)$ & $4(15 \%)$ & $2(10 \%)$ & $1(12 \%)$ \\
\hline \multicolumn{5}{|l|}{ p53 } \\
\hline Negative & $43(80 \%)$ & 24 (92\%) & $12(60 \%)$ & $7(88 \%)$ \\
\hline Positive & $11(20 \%)$ & $2(8 \%)$ & $8(40 \%)$ & $1(12 \%)$ \\
\hline \multicolumn{5}{|l|}{ Grade } \\
\hline $1 a$ & $17(31 \%)$ & $6(23 \%)$ & $9(45 \%)$ & $2(25 \%)$ \\
\hline $1 b$ & $1(2 \%)$ & $1(4 \%)$ & $0(0 \%)$ & $0(0 \%)$ \\
\hline $2 a$ & $23(43 \%)$ & $13(50 \%)$ & $6(30 \%)$ & $4(50 \%)$ \\
\hline $2 b$ & $5(9 \%)$ & $2(8 \%)$ & $3(15 \%)$ & $0(0 \%)$ \\
\hline NA & $8(15 \%)$ & $4(15 \%)$ & $2(10 \%)$ & $2(25 \%)$ \\
\hline \multicolumn{5}{|l|}{ Functioning status } \\
\hline Functioning & $24(44 \%)$ & $0(0 \%)$ & $20(100 \%)$ & $4(50 \%)$ \\
\hline Non-functioning & $30(56 \%)$ & $26(100 \%)$ & $0(0 \%)$ & $4(50 \%)$ \\
\hline
\end{tabular}

* The only characteristic for which $\mathrm{n}$ is different than the one noted on the first row The age at surgery and the maximal diameter are expressed as mean with range Invasion = cavernous and/or sphenoid sinus invasion detected on magnetic resonance imaging and/or during surgery Proliferation $=$ two of three criteria of proliferation present, namely Ki67 index $\geq 3 \%$, mitoses $n>2 / 10$ high power fields (HPFs) ( $400 \times$ magnification), and positive $\mathrm{p} 53$ (>10 strongly positive nuclei/10 HPFs)

number (n), not available (NA)

percentage of intratumoural $\mathrm{S} 100 \mathrm{~B}+$ cells was not statistically associated with the tumour subtype itself (Fig. 3C), a Ki67 index $\geq 3 \%$, a mitosis count $>2 / 10$ HPFs, and a proliferative status, were all significantly associated with a lower percentage of S100B + cells exclusively in gonadotroph tumours (Fig. 3D-F), but not in Pit1, nor in corticotroph tumours (Additional file 2: Fig. S2A-C and Fig. S2E-G). Moreover,
S100B + cells were more widely spread in gonadotroph tumours (range 0.01-9.55\%) compared to Pit1 (range $0-2.17 \%$ ) and corticotroph tumours (range 0.007$3.42 \%)$. No association between invasiveness and the percentage of intratumoural S100B + cells was obtained when considering PitNET subtypes separately (Fig. 3G, Additional file 2: Fig. S2D and S2H). In addition, no statistical significance between the percentage of 


\section{A}
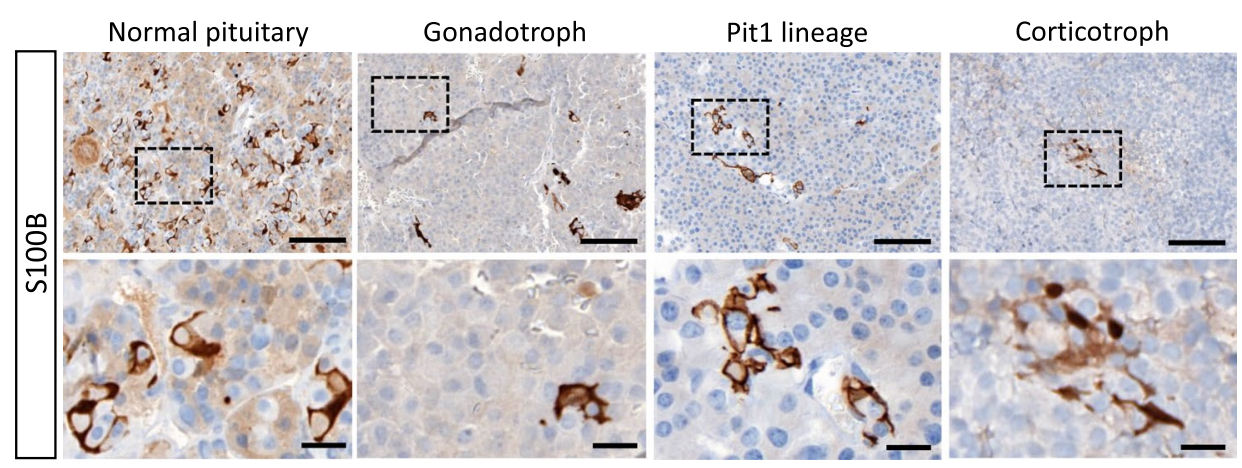

B

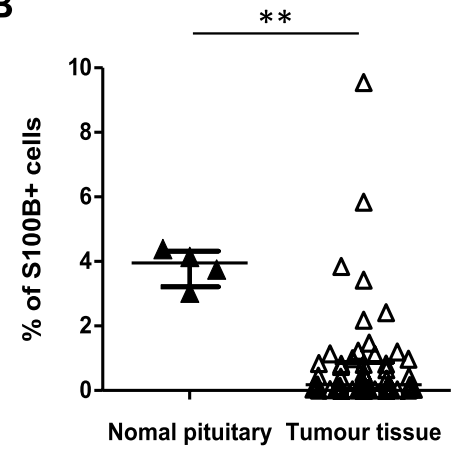

C

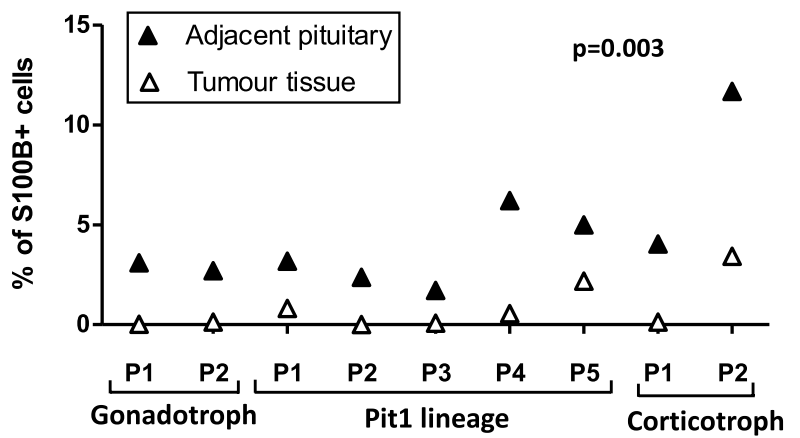

Fig. 2 The percentage of S100B immunoreactive cells is lower in PitNETs compared to the APG. A Representative images of S100B immunoreactive cells found in the normal APG, and in gonadotroph, corticotroph, and Pit1 PitNETs. Lower panels show an enlarged view of the dashed insets. Scale bars $=20 \mu \mathrm{m}$ (top), and $100 \mu \mathrm{m}$ (bottom). B Percentage of S100B + cells in the tumour tissue of 54 PitNETs (median $=0.18 \%$ ) versus 4 normal APG samples (median = 3.95\%). Statistical test: Mann-Whitney, $p=0.003(* *)$. Graph-median with interquartile range. C Percentage of S100B + cells in matching tumour (median $=0.13 \%$, range $0.00 \%-3.42 \%$ ) versus adjacent APG tissue (median $=3.17 \%$, range $1.71-11.68 \%$ ) from 9 patients $(P)$ with PitNETs. Statistical test: Wilcoxon matched paired test. Abbreviations: human pituitary neuroendocrine tumours (PitNETs), anterior pituitary gland (APG)

S100B + cells and other clinicopathological characteristics (age, gender, tumour dimension, grade, and the percentage of SSTR2 + or SSTR5 + cells) was reached in gonadotroph, corticotroph, or Pit1 tumours (Fig. 3H, I and data not shown); of note, SSTR5 was analysed only for corticotroph and Pit1 tumours. Interestingly, the percentage of S100B + cells showed a moderate positive correlation with the percentage of ER $\alpha+$ cells in gonadotroph tumours (Fig. 3J). These observations suggest that intratumoural S100B + cells may play a role in gonadotroph tumorigenesis-related processes.

\section{Spatial analysis of S100B + cell distribution highlights an intratumoural heterogeneity of $\mathrm{S} 100 \mathrm{~B}+$ cells}

Given that our results indicated a possible role for $\mathrm{S} 100 \mathrm{~B}+$ cells in gonadotroph tumorigenesis, we aimed at refining our cartography of this rare population of TME cells, by incorporating a spatial resolution to our analysis. In order to investigate the intratumoural distribution of S100B + cells in our cohort of 26 gonadotroph tumours, we defined for each sample multiple tumour areas on the same tumour slide. The percentage of S100B + cells was then quantified in each area, and the results subsequently confirmed by visually inspecting the stained areas (Fig. 4A). Analysis of the 26 gonadotroph tumours confirmed interpatient heterogeneity, with a subset of tumours displaying almost no S100B expression within the areas quantified and a group of lesions presenting areas with variable percentages of S100B + cells (Fig. 4A, B). Among the latter, the percentage of S100B + cells was heterogeneous between tumours, but also within the different areas of the same tumour, highlighting an intratumoural spatial heterogeneity of S100B + cells in gonadotroph PitNETs (Fig. 4). 

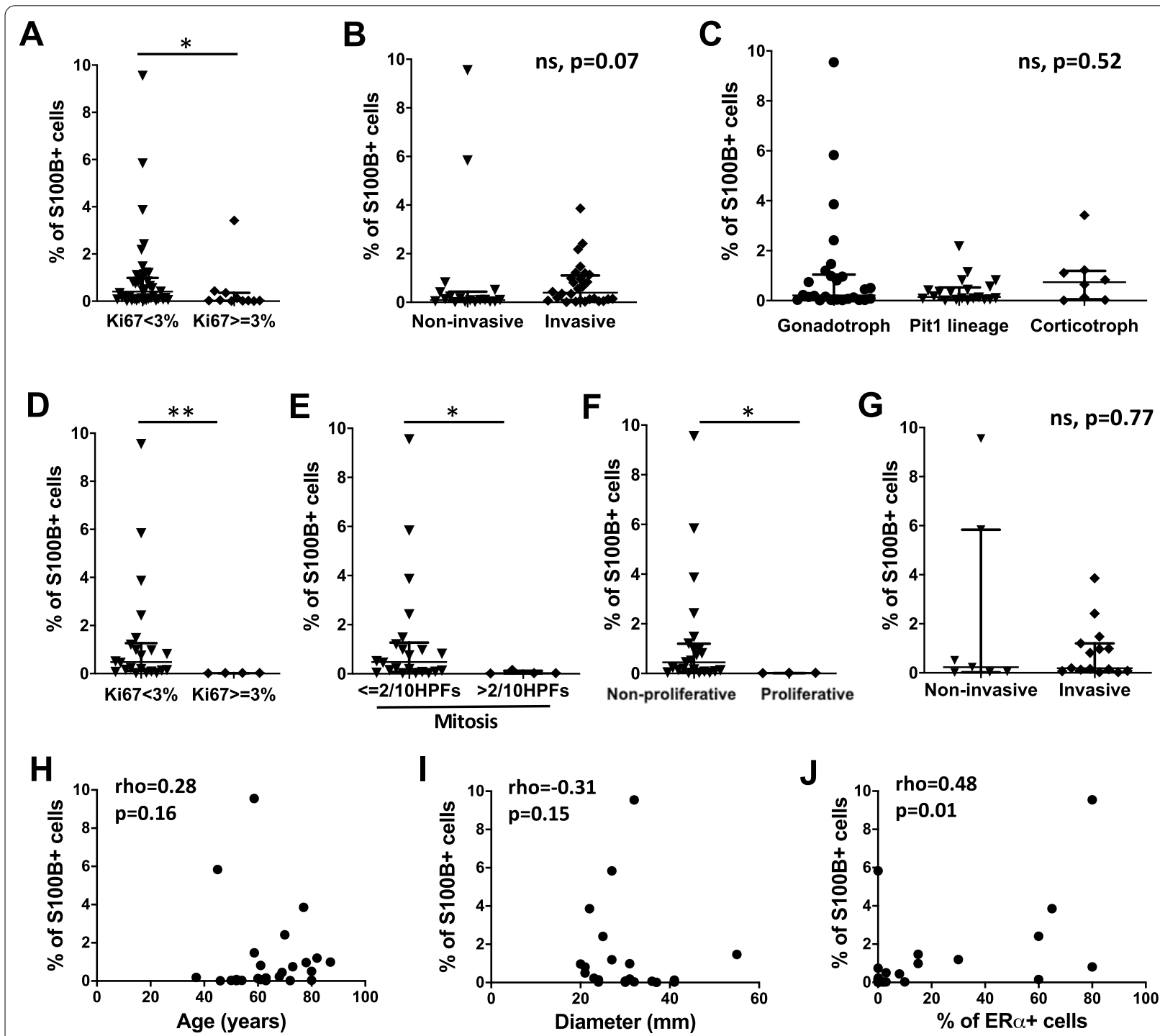

Fig. 3 Association between clinicopathological characteristics and percentage of S100B + cells at the whole tumour level in PitNETs. A Percentage of S100B + cells in PitNETs with a Ki67 index $<3 \%(n=43$, median $=0.40 \%)$ versus a Ki67 index $\geq 3 \%(n=11$, median $=0.02 \%)$, $\left.p=0.01{ }^{*}\right)$. B Percentage of S100B + cells in non-invasive $(n=18$, median $=0.09 \%)$ versus invasive PitNETs $(n=28$, median $=0.39 \%)$. C Percentage of $\mathrm{S} 100 \mathrm{~B}+$ cells in gonadotroph tumours $(n=26$, median $=0.20 \%)$, tumours of the Pit1 lineage $(n=20$, median $=0.14 \%)$, and corticotroph tumours $(n=8$, median $=0.73 \%)$. D Percentage of $5100 B+$ in gonadotroph tumours with a Ki67 index $<3 \%(n=22$, median $=0.47 \%)$ versus a Ki67 index $\geq 3 \%(n=4$, median $=0.02 \%), p=0.007\left({ }^{* *}\right)$. E Percentage of $\mathrm{S100B}+$ cells in gonadotroph tumours with a number of mitosis $\leq 2 / 10$ HPFs $(n=22$, median $=0.47 \%)$ versus a number of mitosis $>2 / 10$ HPFs $(n=4$, median $=0.02 \%), p=0.03(*)$. F Percentage of S100B + cells in non-proliferative $(n=23$, median $=0.44 \%)$ versus proliferative gonadotroph tumours $(n=3$, median $=0.02 \%), p=0.01\left(^{*}\right)$. G Percentage of S100B + cells in non-invasive $(n=7$, median $=0.22 \%)$ versus invasive gonadotroph tumours $(n=15$, median $=0.19 \%)$. $\mathbf{H}$ Correlation analysis between the percentage of $\mathrm{S100B}+$ cells and the age of patients in gonadotroph tumours $(n=26)$. I Correlation analysis between the percentage of S100B + cells and the maximal diameter in gonadotroph tumours $(n=22)$. J Correlation analysis between the percentage of S100B + cells and the percentage of $E R a+$ cells in gonadotroph tumours $(n=25)$. Graphs: median with interquartile range $(\mathbf{A}-\mathbf{G})$, scatter plot $(\mathbf{H}-\mathbf{J})$. Statistical tests: Mann-Whitney $(\mathbf{A}-\mathbf{G})$, Kruskall-Wallis (C), Spearman's correlation $(\mathbf{H}-\mathbf{J})$. Abbreviations: human pituitary neuroendocrine tumours (PitNETs), high power fields (HPFs), non-significant (ns)

The intratumoural spatial distribution of $\mathrm{S} 100 \mathrm{~B}+$ cells is associated with FSH, ERa and Ki67 immunoreactivity The identification of a heterogeneous spatial distribution of $\mathrm{S} 100 \mathrm{~B}+$ cells in individual gonadotroph tumours led us to question whether the spatial distribution of $\mathrm{S} 100 \mathrm{~B}+$ cells may be of functional relevance in these tumours. To address this question, we built a cartography based on the IHC analysis of multiple 


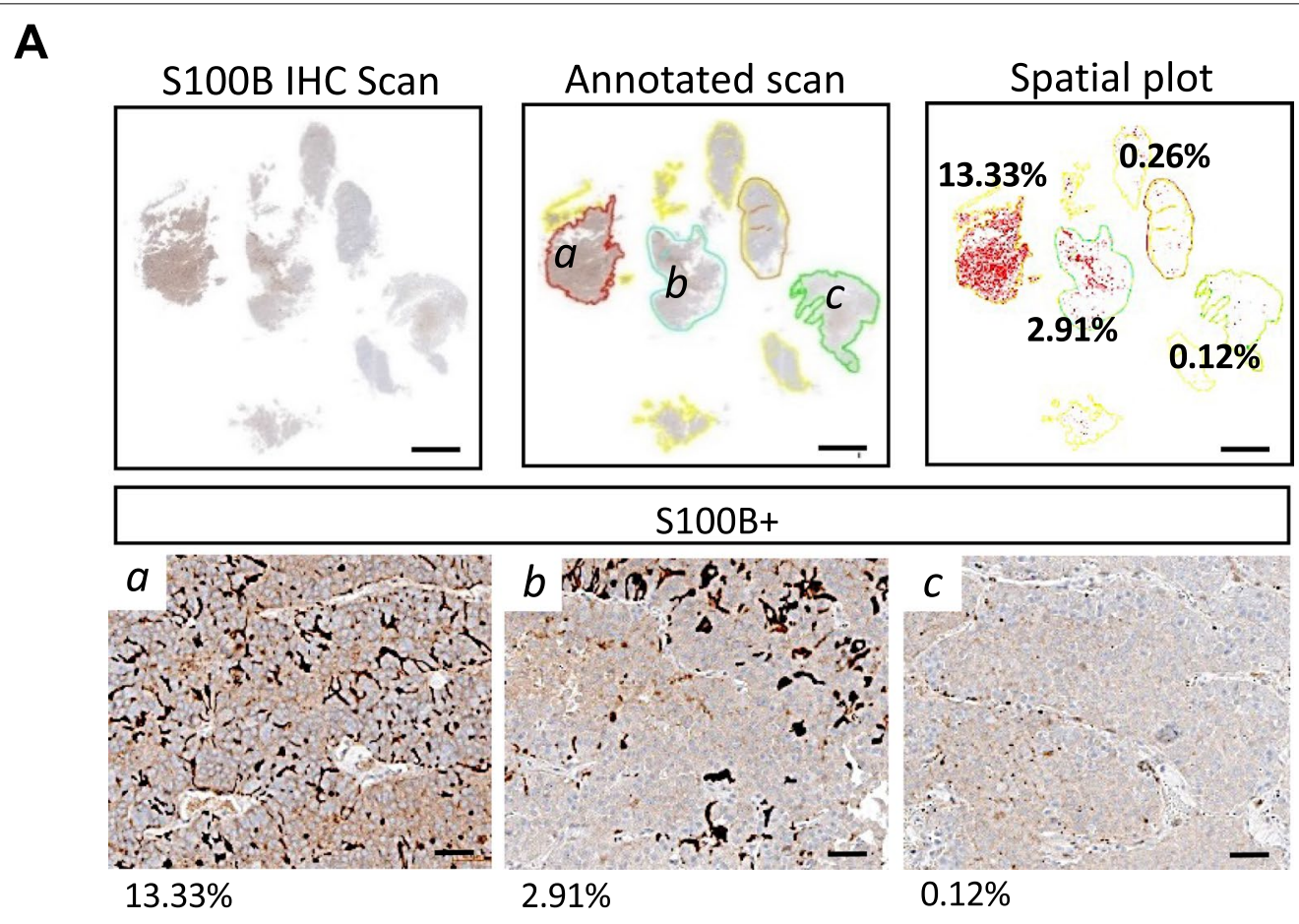

B

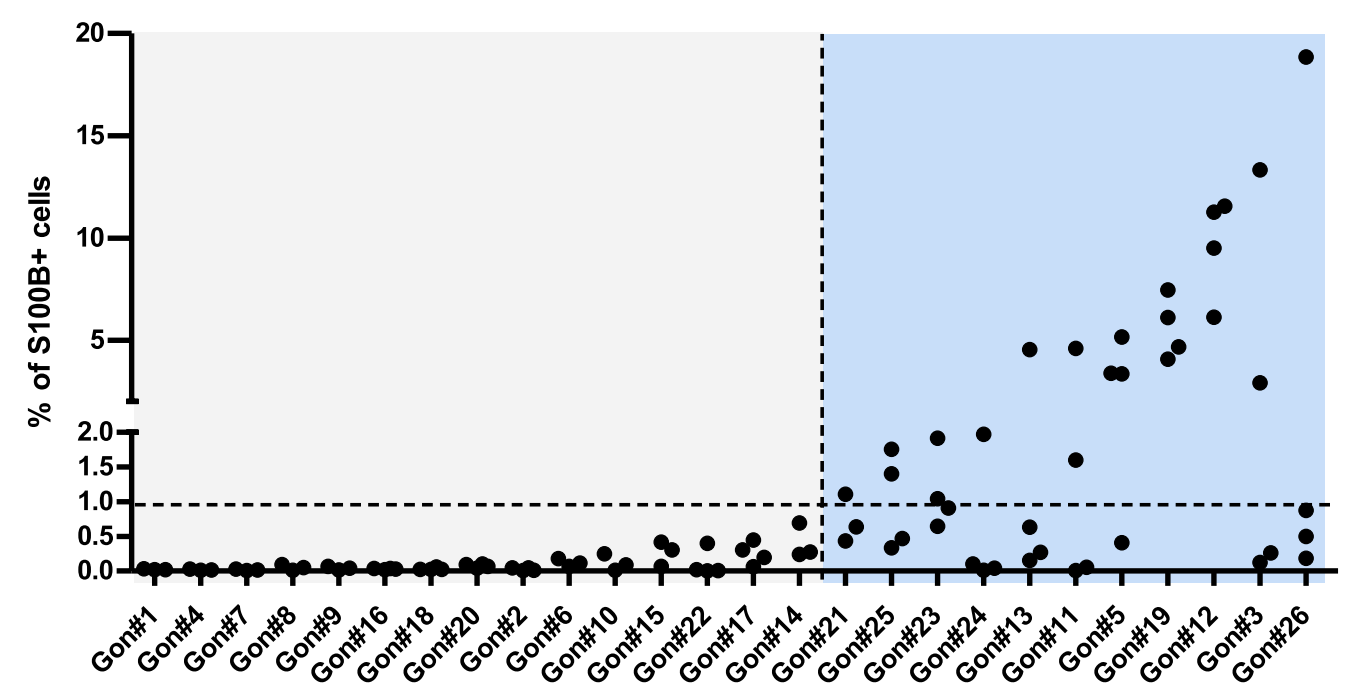

Fig. $4 \mathrm{S100B}$ + cells show an interpatient and an intratumoural heterogeneous distribution in gonadotroph tumours. A Quantification of S100B + cells on a gonadotroph tumour (Gon\#3) showing a variation of more than 100-fold between different areas quantified. Top panel shows the four tumour areas (colour-coded in red, blue, orange, and green) that we defined and quantified on the scanned slide. The spatial plot represents each quantified cell as a red dot, and percentages for each quantified areas are noted. Lower panel shows enlarged views of S100B immunostaining in the indicated area ( $a, b$, and c). Scale bars $=2 \mathrm{~mm}$ (top panel), $50 \mathrm{\mu m}$ (lower panel). B Graph showing the percentage of $\mathrm{S} 100 \mathrm{~B}+$ cells quantified in multiple areas of 26 gonadotroph tumours (Gon\#). Each dot plots the percentage of S100B + cells in a defined tumour area. Horizontal dashed line corresponds to a threshold of 1\% S100B + cells. Vertical dashed line splits gonadotroph tumours with almost no expression of $\mathrm{S100B}$ among quantified areas and gonadotroph tumours presenting areas with variable percentages of detected S100B + cells. Abbreviation: immunohistochemistry $(\mathrm{IHC})$ 


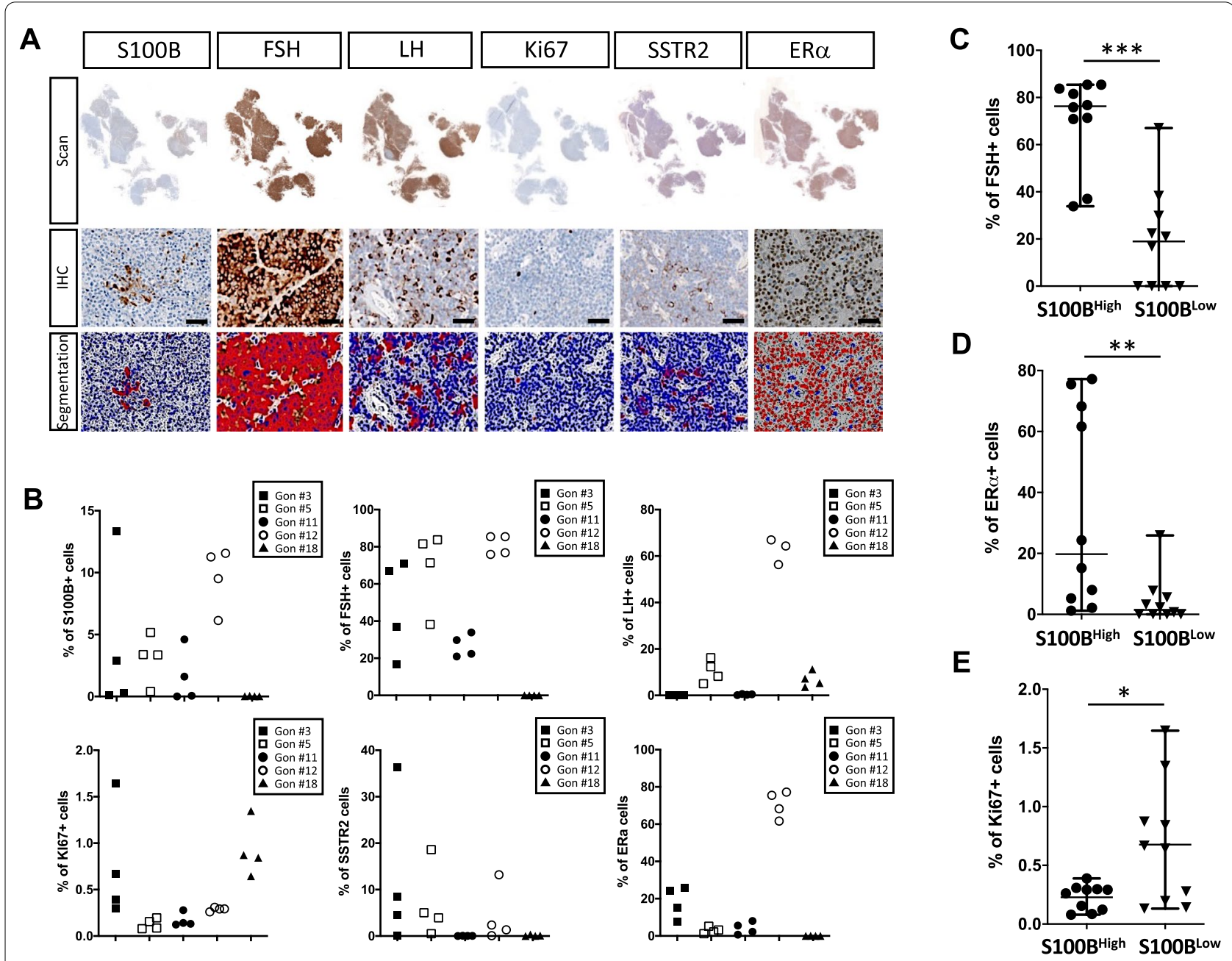

Fig. 5 Spatial analysis of multiple markers provides insight into gonadotroph intratumoural heterogeneity and unravels spatial associations. A Representative images of scans (upper panel), enlarged views of IHC staining (middle panel), and resulting segmentations (lower panel), performed for S100B, FSH, LH, Ki67, SSTR2, and ERa, on serial tumour-sections. Scale bar =50 $\mu \mathrm{m}$. B For each of the five tumours (Gon\#3, \#5, \#11, \#12 and \#18), we annotated the same tumour areas as previously done for the S100B marker (four areas per tumour). The graphs show the distribution of the $\mathrm{S100B}+, \mathrm{FSH}+, \mathrm{LH}+, \mathrm{Ki} 67+\mathrm{SSTR} 2+$, and $\mathrm{ERa}+$ cells, in the resulting 20 independent tumour areas, revealing that these markers were either homogeneously, or heterogeneously distributed within each tumour. Each plotted symbol represents a tumour area. $\mathbf{C}$ Percentage of FSH + cells in $\mathrm{S100B}^{\mathrm{High}}$ (median percentage of FSH + cells $=76.32 \%$ ) versus S100B ${ }^{\text {Low }}$ areas (median percentage of FSH + cells $=18.93 \%$ ), $p=0.00011^{(* *)}$. D Percentage of ERa + cells in S100B ${ }^{\text {High }}$ (median percentage of ERa + cells $=19.78 \%$ ) versus S100B ${ }^{\text {Low }}$ areas (median percentage of $\mathrm{ERa}+$ cells $\left.=1.47 \%), p=0.008{ }^{* *}\right)$. E Percentage of Ki67 + cells in S100B ${ }^{\text {High }}$ (mean percentage of Ki67 + cells $=0.22 \%$ ) versus S100B ${ }^{\text {Low }}$ areas (mean

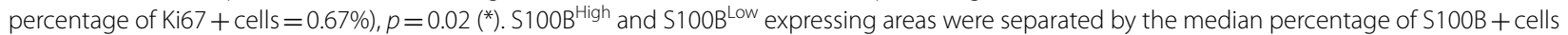
for the 20 areas, $n=10$ for each group. Graphs are as follows: median with range ( $\mathbf{C}$ and $\mathbf{D})$, mean with range (E). Statistical tests: Mann-Whitney $(\mathbf{C}$ and $\mathbf{D})$, Student's t-test with Welch's correction (E). Abbreviations: immunohistochemistry (IHC), follicle-stimulating hormone (FSH), luteinizing hormone (LH), somatostatin receptor type 2 (SSTR2), oestrogen receptor alpha (ERa)

markers on serial tumour sections, including five new markers, namely Ki67 (a proliferation marker), FSH and LH (the two hormones produced by gonadotroph cells), SSTR2 (a potential marker of response to treatment), and ER $\alpha$ (a transcription factor and a potential marker of response to treatment) [26, 30] (Fig. 5A). Spatial quantification of each marker was performed on 20 independent areas of 5 gonadotroph tumours detailed in Table 2 ( 4 areas per tumour). We chose the 5 gonadotroph tumours based on the percentages of S100B + cells: 4 tumours having a heterogeneous distribution, including the tumour having the widest spread of the percentages of $\mathrm{S} 100 \mathrm{~B}+$ cells-gonadotroph tumour \#3, and one tumour having homogeneous percentages of S100B + cells-gonadotroph tumour \#18. 
Table 2 Clinicopathological characteristics of the 5 gonadotroph tumours for which serial tissue-sections were analysed

\begin{tabular}{|c|c|c|c|c|c|}
\hline & Gonadotroph \#3 & Gonadotroph \#5 & Gonadotroph \#11 & Gonadotroph \#12 & $\begin{array}{l}\text { Gonadotroph } \\
\# 18\end{array}$ \\
\hline Age at surgery (years) & 77 & 87 & 58 & 58 & 52 \\
\hline Gender & Female & Male & Male & Male & Male \\
\hline Maximal diameter (mm) & 22 & 31 & 55 & 32 & 41 \\
\hline Invasion & Yes & Yes & Yes & No & Yes \\
\hline Proliferation & No & No & No & No & Yes \\
\hline Grade & $2 \mathrm{a}$ & $2 \mathrm{a}$ & $2 a$ & $1 a$ & $2 b$ \\
\hline
\end{tabular}

The spatial quantification of each marker shown in Fig. 5B revealed their heterogeneous distribution between the different tumours. In these 5 tumours, the percentage of ER $\alpha$-expressing and LH-expressing cells seemed to show less intratumoural heterogeneity than S100B-expressing, FSH-expressing, Ki67-expressing, and SSTR2-expressing cells (Fig. 5B). For each area, we further questioned the spatial association of the tested markers with the percentage of $\mathrm{S} 100 \mathrm{~B}+$ cells. Areas expressing low and high levels of S100B were defined based on the median percentage of S100B + cells within the 20 areas ( $\mathrm{n}=10$ for each group). $\mathrm{S} 100 \mathrm{~B}^{\text {High }}$ areas had significantly more FSH + and $\mathrm{ER} \alpha+$ cells $(p=0.0001$, and $p=0.008$, respectively) (Fig. 5C, D, Fig. 6A, Additional file 3: Fig. S3A) and fewer Ki67 + cells $(p=0.02)$ (Fig. 5E, Additional file 3: Fig. S3B). The percentage of $\mathrm{LH}+$ and SSTR2 + cells was not significantly different between S100B ${ }^{\text {High }}$ and S100B ${ }^{\text {Low }}$ tumour areas (Additional file 4: Fig. S4). Correlation analysis of the 20 tumour areas further confirmed that the percentage of $\mathrm{S} 100 \mathrm{~B}+$ cells was positively and strongly correlated with the percentage of $\mathrm{FSH}+$ cells (Spearman's rho $=0.78$, adjusted $p=0.0007$ ) and of ER $\alpha+$ cells (Spearman's rho $=0.76$, adjusted $p=0.001$ ) (Table 3). A strong positive correlation was also found between the percentage of FSH+cells and $\mathrm{ER} \alpha+$ cells (Spearman's rho $=0.67$, adjusted $p=0.01$ ) (Table 3), suggesting the existence of tumour areas simultaneously rich and poor in $\mathrm{FSH}+, \mathrm{ER} \alpha+$, and S100B + cells (Additional file 3: Fig. S3C).

To further validate these associations, we confirmed the existence of gonadotroph tumour areas presenting either an enrichment in S100B, ER $\alpha$, and FSH immunoreactivity, or a lack of immunoreactivity for the three markers (Fig. 6B). Double IF S100B/FSH staining also revealed that $\mathrm{S} 100 \mathrm{~B}$ + cells were mainly located in areas enriched in FSH immunoreactivity (Fig. 6C). Hence, these observations confirmed the heterogeneous nature of gonadotroph tumours, and suggest that the heterogeneous distribution of $\mathrm{S100B}+$ cells might be of functional relevance within the TME of gonadotroph PitNETs.

\section{Discussion}

The concepts of intratumoural, intertumoural and interpatient heterogeneity are intensively studied and acknowledged to be of tremendous importance in cancer biology [31, 32]. In PitNETs, tumour heterogeneity has only started to be unravelled by recent studies [30, $33,34]$. Here, our work contributes to extending this knowledge by providing an insight into the heterogeneity of PitNETs through the cartography of a rare TME component, namely S100B-expressing FS cells. Our work presents a novel high-throughput histological approach to analyse the spatial distribution and the association of multiple markers on scanned whole sections. To our knowledge, this report is the first to investigate the intratumoural spatial distribution of FS cells, and even gonadotroph intratumoural heterogeneity in general. As illustrated by our results, this kind of approach may refine our knowledge of tumour heterogeneity and favour the identification of functional associations between TME components and tumour cells.

Using whole-scan quantification of S100B IHC staining, we first confirmed an overall loss of S100B + FS cells in the majority of our PitNETs compared to normal APG and to adjacent APG, with $80 \%$ of these tumours having $<1 \% \quad \mathrm{~S} 100 \mathrm{~B}+$ cells, and $35 \%$ having $<0.1 \%$ $\mathrm{S} 100 \mathrm{~B}+$ cells. This result is consistent with previous work that reported a loss of S100B + cells in PitNETs in comparison to normal APG collected from autopsies or from APG regions adjacent to tumour tissue $[19,35]$. Interestingly, our analysis further revealed an interpatient heterogeneity with percentages of $\mathrm{S} 100 \mathrm{~B}+$ cells ranging from 0 to $9.55 \%$ in the 54 PitNETs analysed. Among PitNET subtypes, gonadotroph tumours had the most variable S100B distribution, though this may be partly due to our cohort composition.

Retrospective investigation of clinicopathological characteristics revealed that PitNETs with a Ki67 index $\geq 3 \%$ were associated with fewer S100B + cells. Further analysis comparing PitNET subtypes, pointed this proliferative trait to be driven by the gonadotroph subtype. Indeed, in gonadotroph tumours, not only was 

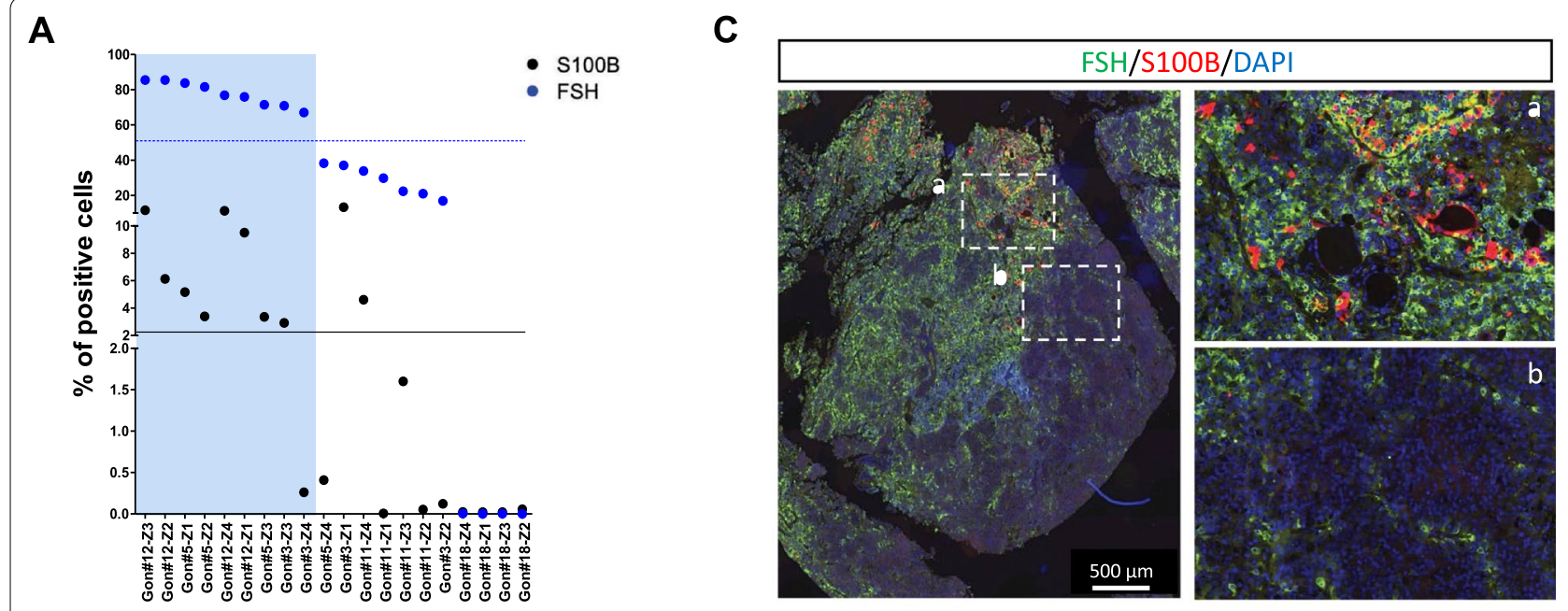

B
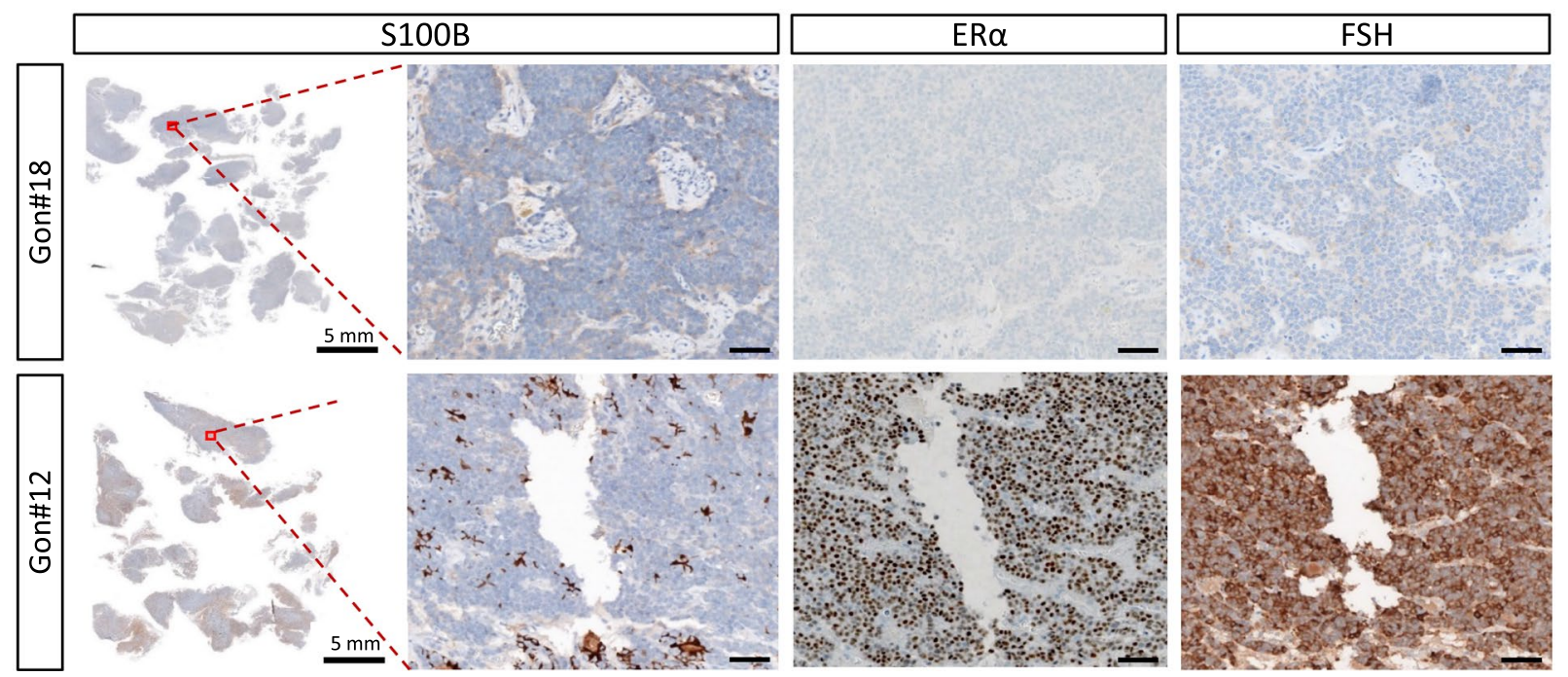

Fig. 6 S100B-enriched areas are also enriched in FSH- and ERa-expressing cells in gonadotroph tumours. A Graph showing the percentage of S100B + cells and FSH + cells in 20 matching tumour areas (Z1 to Z4) of 5 gonadotroph tumours (Gon\#3, \#5, \#11, \#12 and \#18). The areas represented on the right side (blue background) show the highest percentages of FSH + cells. Black and blue lines delineate the higher versus lower percentages of $\mathrm{S} 100 \mathrm{~B}+$, and FSH + cells, respectively. The higher versus lower percentages of S100B + cells are split by the median. B Representative images of S100B, ERa, and FSH IHC staining performed on serial sections of two gonadotroph tumours. Left panel shows scanned S100B IHC slide. Right panels are enlarged views of the indicated areas (red squares). For each tumour, ERa and FSH staining are shown in the matching areas of serial sections. Scale bar $=50 \mu \mathrm{m}$. C Representative image of a double immunofluorescence staining for S100B (red) and FSH (green) performed on a gonadotroph tumour. Right panel shows enlarged views of the $a$ and $b$ dashed areas area. Abbreviations: immunohistochemistry $(\mathrm{IHC})$, follicle-stimulating hormone (FSH), oestrogen receptor alpha (ERa)

a Ki67 index $\geq 3 \%$ significantly associated with fewer S100B + cells, but also a mitosis count $>2 / 10$ per HPFs, and the proliferative status. While we also found the overall percentage of S100B + cells to positively correlate with the percentage of ER $\alpha+$ cells in gonadotroph tumours, the overall percentage of S100B + cells was not associated with age, gender, invasion or tumour dimension in any of the PitNET subtypes, a result consistent with previous work by Voit et al. in acromegaly patients [25]. Moreover, the percentage of intratumoural S100B + cells was not statistically associated with the grade, and did not correlate with the percentage of SSTR2 + cells in any of the PitNET subtypes. In Pit1 and in corticotroph tumours, this percentage was not associated with proliferation markers, and did not correlate with the percentage of SSTR5 + cells, either. Of note, in gonadotroph tumours, it would have been interesting to also compare S100B + cells 
Table 3 Correlation matrix between the 6 markers analysed in 20 tumour areas of 5 gonadotroph tumours

\begin{tabular}{|c|c|c|c|c|c|c|}
\hline & $E R a \%$ & $\mathrm{FSH} \%$ & Ki67\% & LH\% & $\mathrm{S} 100 \mathrm{~B} \%$ & SSTR2\% \\
\hline \multicolumn{7}{|c|}{ Spearman's rho/adjusted p-value (Holm's method)/n } \\
\hline $\mathrm{ERa} \%$ & & $0.67 / 0.01 / 20$ & $-0.10 / 1 / 20$ & $0.01 / 1 / 19$ & $0.76 / 0.001 / 20$ & $0.40 / 0.72 / 20$ \\
\hline $\mathrm{FSH} \%$ & $0.67 / 0.01 / 20$ & & $-0.50 / 0.23 / 20$ & $0.43 / 0.60 / 19$ & $0.78 / 0.0007 / 20$ & $0.55 / 0.12 / 20$ \\
\hline Ki67\% & $-0.10 / 1 / 20$ & $-0.50 / 0.23 / 20$ & & $-0.21 / 1 / 19$ & $-0.31 / 1 / 20$ & $0.01 / 1 / 20$ \\
\hline $\mathrm{LH} \%$ & $0.01 / 1 / 19$ & $0.43 / 0.60 / 19$ & $-0.21 / 1 / 19$ & & $0.31 / 1 / 19$ & $0.13 / 1 / 19$ \\
\hline S100B\% & $0.76 / 0.002 / 20$ & $0.78 / 0.0007 / 20$ & $-0.31 / 1 / 20$ & $0.31 / 1 / 19$ & & $0.34 / 1 / 20$ \\
\hline SSTR2\% & $0.40 / 0.72 / 20$ & $0.55 / 0.12 / 20$ & $0.01 / 1 / 20$ & $0.13 / 1 / 19$ & $0.34 / 1 / 20$ & \\
\hline
\end{tabular}

The correlations with an adjusted p-value (Holm's method) $<0.05$ are written in bold letters

oestrogen receptor alpha (ERa), follicle-stimulating hormone (FSH), luteinizing hormone (LH), somatostatin receptor type 2 (SSTR2), number of patients for which the data are available $(n)$

to SSTR3 + cells. Although the absence of statistically significant associations might be due to small sample sizes, these observations support nevertheless the hypothesis that $\mathrm{S} 100 \mathrm{~B}+$ cells may have distinct functions in different PitNET subtypes, and that the loss of these cells could favour the proliferative status of gonadotroph tumours.

Spatial analysis of cell distribution in different tumour areas of 26 gonadotroph PitNETs further revealed an intratumoural heterogeneity of S100B + cells. While we identified a first group of gonadotroph tumours with almost no S100B + cells, we found a second group that presented a wide distribution of $\mathrm{S} 100 \mathrm{~B}+$ cells ranging from 0.005 to $18.85 \%$ within different areas analysed. The presence of an intratumoural heterogeneity and the existence of low- and high-expressing S100B areas was intriguing and made us question the functional consequences of such a spatial cell distribution in gonadotroph tumours. To address this question, we added to our spatial analysis 5 new markers: Ki67, FSH, LH, ER $\alpha$ and SSTR2. Analysing 20 areas from 5 independent gonadotroph tumours, we found that higher percentages of $\mathrm{S} 100 \mathrm{~B}+$ cells were associated with lower percentages of Ki67. This observation was consistent with our previous observation based on the overall percentage of S100B + cells per tumour, and it further confirmed the functional relationship that may exist between gonadotroph tumour proliferation and the loss of S100B + cells.

More interestingly, through our spatial analysis, we observed strong positive correlations between the percentage of S100B + cells and FSH + cells, and between $\mathrm{S} 100 \mathrm{~B}+$ cells and ER $\alpha+$ cells, respectively. A similar correlation was also found between the percentage of $\mathrm{FSH}+$ cells and ER $\alpha+$ cells, suggesting the occurrence of tumour areas simultaneously rich and poor in FSH +, $\mathrm{ER} \alpha+$, and $\mathrm{S} 100 \mathrm{~B}+$ cells. Consistently, a positive correlation between FSH and ER $\alpha$ at the whole tumour level has already been reported in gonadotroph tumours [30,
36], suggesting that our technical approach is appropriate to investigate spatial associations of marker co-expression. Given the fact that ER $\alpha$ is also expressed in the vast majority of normal human gonadotroph cells which produce, secrete and stain for FSH [37, 38], we hypothesize that gonadotroph tumour cells expressing ER $\alpha$ and FSH might be closer to a normal phenotypic state than gonadotroph tumour cells lacking ER $\alpha$ and FSH expression. Identification of an enrichment in S100B + folliculostellate cells in areas also enriched in ER $\alpha$-expressing and FSH-expressing cells may suggest a role for these cells in maintaining a more differentiated, functioning or closer to the normal phenotype state of gonadotroph tumour cells. This hypothesis appears to be coherent with our other findings, as the loss of intratumoural S100B + cells was associated with increased proliferation. Alternatively, FS cells may secrete cofactors that modulate the signalling of oestrogens through ER $\alpha$ [39] leading to FSH production, or FS cells may secrete molecules or physically interact with gonadotroph tumour cells leading to FSH production independently of ER $\alpha$. Such molecules might be IL- 6 or transforming growth factor $\beta$, both of which were shown to be produced by FS cells $[22,40]$, and to stimulate the secretion of FSH by the normal APG [40, 41]. Indeed, given that FS cells have been shown to modulate the hormone secretion of the normal APG [22] and that relationships between $\mathrm{S} 100 \mathrm{~B}+$ cells and the preoperative levels of growth hormone and of prolactin were revealed in acromegaly patients [25], it would not be surprising if FS cells also have an effect on hormone production/secretion by gonadotroph tumour cells.

Knowing that FS cells produce a large numbers of secreted cytokines, it would be tempting to speculate that FS cells could modulate tumour cell behaviour through paracrine signalling, by acting, for example, as a senescence inducer and/or proliferation controller. Interestingly, the secretion of the senescence-associated IL- 6 cytokine by FS cells was shown to inhibit 
the proliferation of endocrine cells in the normal APG [40]. In pituitary tumours, it has been shown that IL-6 was mainly produced by tumour cells [40, 42], and that its silencing in primary cultures of human pituitary tumours decreased tumour senescence [43]. To the same extent, FS cells also produce follistatin [22], which may be another interesting candidate since dysregulation of follistatin function was shown to be linked to multiple cancers, including pituitary adenomas [44]. Our results highlight therefore the need for refining our knowledge on the secretome of intratumoural S100B + cells since it could have potent actions in PitNETs.

Aside from their possible function in gonadotroph tumours and other PitNETs, one may question whether FS cells may act as "gatekeeper" cells involved in maintaining normal structure and function of the APG, and whether their loss might favour the onset of pituitary tumours. Studies on the normal human APG have shown an increased presence of S100B + cells with age, especially after the age of $70[45,46]$, and proposed that the increased presence of these cells represents the successful modality of APG aging [45]. Given the multiple roles FS cells have in the normal APG through paracrine $[17,22]$ and physical actions $[47,48]$, it appears indeed possible that these cells are necessary to maintain a normal tissue structure and function. Their loss might therefore shift the balance from normal tissue preservation to adenoma formation/progression. And, reciprocally, a normal APG tissue might be required to maintain the presence of FS cells.

\section{Conclusions}

We conducted an interpatient and an intratumoural cartography of S100B + cells to gain insight into the potential functions these cells might have in gonadotroph tumours. Concomitantly, we demonstrated the feasibility of analysing whole tumour sections at the single-cell resolution in human PitNETs, and of spatially analysing multiple markers on serial sections. The overall percentage of $\mathrm{S} 100 \mathrm{~B}+$ cells was associated with lower proliferative properties and positively correlated with ER $\alpha$ expression in gonadotroph tumours. However, the overall percentage of S100B + cells was not associated/correlated with age, gender, invasion, grade, tumour dimension and percentage of SSTR2 + cells in any of the PitNET subtypes. In Pit1 and in corticotroph tumours, this percentage was not associated with proliferation markers, and did not correlate with the percentage of SSTR $5+$ cells, either. Our work highlights a potential role for intratumoural $\mathrm{S} 100 \mathrm{~B}+$ cells in modulating the proliferation, the differentiation, and the hormonal production of gonadotroph tumour cells. It also suggests that $\mathrm{S100B}+$ cells may contribute to maintaining a phenotype closer to the normal tissue in certain tumour areas. However, the importance of $\mathrm{S} 100 \mathrm{~B}+$ cell loss in pituitary tumorigenesis remains to be demonstrated. Our work paves the way towards a refined view of gonadotroph tumour heterogeneity and towards a better understanding of the role of $\mathrm{S} 100 \mathrm{~B}+$ folliculostellate cells in gonadotroph tumours. It also emphasizes the need to perform high-resolution analysis of the TME at the single-cell level to unravel novel mechanisms that drive tumorigenesis-associated processes, which will hopefully lead to the discovery of new diagnostic and prognostic markers and of new and/ or personalized treatments.

\section{Abbreviations}

APG: Anterior pituitary gland; FSH: Follicle-stimulating hormone; FS: Folliculostellate; FFPE: Formalin-fixed paraffin embedded; HPFs: High power fields; IF: Immunofluorescence; IHC: Immunohistochemistry; IL-6: Interleukin 6; LH: Luteinizing hormone; ERa: Oestrogen receptor alpha; PitNETs: Pituitary neuroendocrine tumours; SSTR2: Somatostatin receptor type 2; SF1: Steroidogenic factor 1;TME:Tumour microenvironment.

\section{Supplementary Information}

The online version contains supplementary material available at https://doi. org/10.1186/s40478-022-01321-y.

Additional file 1: Fig. S1. Representative S100B immunohistochemical (IHC) staining and segmentation. A, Representative immunostaining patterns of S100B in tumour tissue and adjacent anterior pituitary. Left panel shows a scanned S100B immunostained section of a gonadotroph tumour. Right panels are magnified views of the observed staining in the adjacent anterior pituitary and tumour tissue present on the same slide (adjacent anterior pituitary is annotated in blue). Scale bar $=50 \mu \mathrm{m}$. B, Representative example of a single-cell segmentation performed with the HALO ${ }^{\circledR}$ software (Indica Labs, New Mexico, USA): S100B IHC staining (top), and the resulting segmentation (bottom) are shown. Nuclei are segmented in blue, while the positive staining is segmented in red.

Additional file 2: Fig. S2. Association between the percentage of S100B+ cells and clinicopathological traits in Pit1 and corticotroph tumours. A, Percentage of $\mathrm{S100B}+$ cells in Pit1 tumours with a Ki67 index $<3 \%(\mathrm{n}=$ 16 , median $=0.14 \%$ ) versus a Ki67 index $\geq 3 \%(n=4$, median $=0.19 \%)$. B, Percentage of $\mathrm{S100B}+$ cells in Pit1 tumours with a number of mitosis $\leq 2 / 10$ HPFs $(n=18$, median $=0.11 \%$ ) versus a number of mitosis $>2 / 10$ HPFs ( $n=2$, median $=0.39 \%)$. C, Percentage of S100B+ cells in nonproliferative ( $n=16$, median $=0.14 \%$ ) versus proliferative Pit1 tumours ( $n$ $=4$, median $=0.19 \%)$. $\mathbf{D}$, Percentage of S100B + cells in non-invasive $(\mathrm{n}=$ 9 , median $=0.09 \%$ ) versus invasive Pit1 tumours $(n=9$, median $=0.35 \%$ ). E, Percentage of S100B + cells in corticotroph tumours with a Ki67 index $<3 \%(n=5$, median $=0.83 \%)$ versus a Ki67 index $\geq 3 \%(n=3$, median $=0.13 \%)$. F, Percentages of S100B + cells in corticotroph tumours with a number of mitosis $\leq 2 / 10 \mathrm{HPFs}(\mathrm{n}=7$, median $=0.64 \%$ ) versus a number of mitosis $>2 / 10$ HPFs $(n=1$, median $=1.11 \%)$. G, Percentage of S100B+ cells in non-proliferative $(n=7$, median $=0.64 \%)$ versus proliferative corticotroph tumours $(n=1$, median $=1.11 \%)$. $\mathbf{H}$, Percentage of S100B+ cells in non-invasive $(n=2$, median $=0.07 \%)$ versus invasive corticotroph tumours $(n=4$, median $=0.74 \%$ ). Graphs show median with interquartile range. Statistical test: Mann-Whitney. Abbreviations: non-significant (ns), high power fields (HPFs). 
Additional file 3: Fig. S3. Spatial association between S100B+, ERa+, $\mathrm{Ki} 67+$, and FSH+ cells. A, Graph showing the percentage of S100B+ cells and $E R a+$ cells in 20 matching tumour areas (Z1 to Z4) of 5 gonadotroph

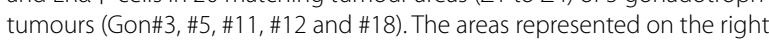
side (red background) show the highest percentage of ERa+ cells. Black and red lines delineate the higher versus lower percentages of S100B+ cells, and ER + cells, respectively. The higher versus lower percentages of $\mathrm{S} 100 \mathrm{~B}+$ cells are separated by the median. B, Graph showing the percentage of $\mathrm{S100B}+$ cells and Ki67+ cells in 20 matching tumour areas (Z1 to Z4) of 5 gonadotroph tumours (Gon\#3,\#5, \#11,\#12 and \#18). The areas represented on the right side (green background) show the highest percentages of Ki67+ cells. Black and green lines delineate the higher versus lower percentages of S100B + cells, and Ki67+ cells, respectively. The higher versus lower percentages of $\mathrm{S} 100 \mathrm{~B}+$ cells are separated by the median. C, Graph showing the percentage of S100B + cells, FSH+ cells, and ERa + cells, in 20 matching tumour areas (Z1 to Z4) of 5 gonadotroph

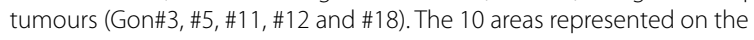
right side (grey background) show the highest percentage of S100B+ cells (the higher versus lower percentages of S100B + cells are split by the median). Blue and red lines delineate the higher versus lower percentages of FSH+, and ERa+ cells, respectively. Abbreviations: follicle-stimulating hormone (FSH), oestrogen receptor alpha (ERa)

Additional file 4: Fig. S4. The percentage of $\mathrm{LH}+$ and SSTR2 + cells was not associated with the percentage of $\mathrm{S100B}+$ cells in gonadotroph tumours. A, Percentage of $\mathrm{LH}+$ cells in $\mathrm{S1}_{100 B^{H i g h}}(\mathrm{n}=9$, median percentage of $L H+$ cells $=12.32 \%)$ versus $S 100 B^{\text {Low }}$ areas $(n=10$, median percentage of $\mathrm{LH}+$ cells $=2.01 \%$ ). B, Percentage of SSTR2 + cells in S100B ${ }^{\text {High }}$ $\left(n=10\right.$, median percentage of SSTR2 + cells $=3.13 \%$ ) versus S100B $B^{\text {Low }}$ areas $(n=10$, median percentage of SSTR2+ cells $=0.08 \%)$. S100B ${ }^{\text {High }}$ and $\mathrm{S}_{100 \mathrm{~B}^{\mathrm{LOw}}}$ expressing areas were separated by the median percentage of S100B + cells for the 20 areas. Graphs show median with range. Statistical test: Mann-Whitney, ns=non-significant. Abbreviations: luteinizing hormone (LH), somatostatin receptor type 2 (SSTR2).

\section{Acknowledgements}

The authors thank CRB HCL-Tissue Tumorothèque Est for its assistance with biological samples, and Dr Brigitte MANSHIP for English proofreading.

\section{Authors' contributions}

Conceptualization: PB, GR; Methodology: MDI, AV, MC, NG, AH, GR, PB; Material preparation: AV, MC, LC; Histological analysis: MDI, AV; Statistical analysis: MDI; Writing the initial manuscript: MDI, PB; Editing: MDI, AH, PB, GR; Supervision: PB, GR. All authors read and approved the final manuscript.

\section{Funding}

This work has been supported by the Exchange in Endocrinology Expertise (3E) program award of the European Union of Medical Specialists (UEMS), Section and Board of Endocrinology, Fondation ARC pour la recherche sur le cancer (PJA 20181207935 and ARCMD-DOC12020020001361), La Ligue contre le cancer, Région Rhone-Alpes-Auvergne, and La Société Française d'Endocrinologie (FRIEMM). These funding bodies had no role in the design of the study, nor in the collection, analysis, and interpretation of data, or in writing the manuscript.

\section{Availability of data and materials}

Not applicable.

\section{Declarations}

\section{Ethics approval and consent to participate}

The study was performed in line with the principles of the Declaration of Helsinki and its later amendments, and was approved by the bioethics committees of Hospices Civils de Lyon (No. 21_439) and of Targu Mures Hospital (No. 5894). Patient information was recorded in a local database (PITUICARELyon, registered with the French data protection agency CNIL, 16-021, and clinicaltrials.org, NCT 02854228). Informed consent was obtained from all individual patients included in the study.

\section{Consent for publication}

Not applicable.

\section{Competing interests}

The authors declare that they have no competing interests.

\section{Author details}

'Inserm U1052, CNRS UMR5286, University Claude Bernard Lyon 1, Cancer Research Center of Lyon, Lyon, France. ${ }^{2}$ Endocrinology Department, "C.I. Parhon" National Institute of Endocrinology, Bucharest, Romania. ${ }^{3}$ Pathology Department, Reference Center for Rare Pituitary Diseases HYPO, "Groupement Hospitalier Est" Hospices Civils de Lyon, Bron, France. ${ }^{4}$ Pathology Research Platform, Department of Translational Research and Innovation, Centre Leon Berard, Lyon, France. ${ }^{5}$ Pathology Department, Targu Mures Emergency Hospital, Targu Mures, Romania. ${ }^{6}$ Histology Department, Pharmacy, Science and Technology of Targu Mures, University of Medicine, Targu Mures, Romania. ${ }^{7}$ Neurosurgery Department, Reference Center for Rare Pituitary Diseases HYPO, "Groupement Hospitalier Est" Hospices Civils de Lyon, Bron, France. ${ }^{8}$ Endocrinology Department, Reference Center for Rare Pituitary Diseases HYPO, Groupement Hospitalier Est" Hospices Civils de Lyon, Bron, France.

Received: 29 November 2021 Accepted: 24 January 2022

Published online: 09 February 2022

\section{References}

1. Asa SL, Casar-Borota O, Chanson P, Delgrange E, Earls P, Ezzat S et al (2017) From pituitary adenoma to pituitary neuroendocrine tumor (PitNET): an International Pituitary Pathology Club proposal. Endocr Relat Cancer 24:C5-8

2. Melmed S (2020) Pituitary-tumor endocrinopathies. N Engl J Med 382:937-950

3. Raverot G, llie MD, Lasolle H, Amodru V, Trouillas J, Castinetti F et al (2021) Aggressive pituitary tumours and pituitary carcinomas. Nat Rev Endocrinol 17:671-684

4. Nishioka H, Inoshita N, Mete O, Asa SL, Hayashi K, Takeshita A et al (2015) The complementary role of transcription factors in the accurate diagnosis of clinically nonfunctioning pituitary adenomas. Endocr Pathol 26:349-355

5. Drummond J, Roncaroli F, Grossman AB, Korbonits M (2019) Clinical and pathological aspects of silent pituitary adenomas. J Clin Endocrinol Metab 104:2473-2489

6. Ilie MD, Raverot G (2020) Treatment options for gonadotroph tumors: current state and perspectives. J Clin Endocrinol Metab 105:e3507-e3518

7. Raverot G, Dantony E, Beauvy J, Vasiljevic A, Mikolasek S, Borson-Chazot F et al (2017) Risk of recurrence in pituitary neuroendocrine tumors: a prospective study using a five-tiered classification. J Clin Endocrinol Metab 102:3368-3374

8. Raverot G, Vasiljevic A, Jouanneau E (2018) Prognostic factors of regrowth in nonfunctioning pituitary tumors. Pituitary 21:176-182

9. Raverot G, Burman P, McCormack A, Heaney A, Petersenn S, Popovic $\checkmark$ et al (2018) European Society of Endocrinology Clinical Practice Guidelines for the management of aggressive pituitary tumours and carcinomas. Eur J Endocrinol 178:G1-24

10. Asa SL, Ezzat S (2016) Aggressive pituitary tumors or localized pituitary carcinomas: defining pituitary tumors. Exp Rev Endocrinol Metab 11:149-162

11. McCormack A, Dekkers OM, Petersenn S, Popovic V, Trouillas J, Raverot G et al (2018) Treatment of aggressive pituitary tumours and carcinomas: results of a European Society of Endocrinology (ESE) survey 2016. Eur J Endocrinol 178:265-276

12. Balkwill FR, Capasso M, Hagemann T (2012) The tumor microenvironment at a glance. J Cell Sci 125:5591-5596

13. Hui L, Chen $Y$ (2015) Tumor microenvironment: sanctuary of the devil. Cancer Lett 368:7-13

14. Ilie MD, Vasiljevic A, Raverot G, Bertolino P (2019) The microenvironment of pituitary tumors-biological and therapeutic implications. Cancers 11:1605 
15. Marques $P$, Grossman $A B$, Korbonits $M$. The tumour microenvironment of pituitary neuroendocrine tumours. Front Neuroendocrinol. 2020;58:100852

16. Nakajima T, Yamaguchi H, Takahashi K (1980) S100 protein in folliculostellate cells of the rat pituitary anterior lobe. Brain Res 191:523-531

17. Morris J, Christian H (2011) Folliculo-stellate cells: paracrine communicators in the anterior pituitary. Open Neuroendocrinol J 4:77-89

18. Allaerts W, Vankelecom $\mathrm{H}$ (2005) History and perspectives of pituitary folliculo-stellate cell research. Eur J Endocrinol 153:1-12

19. Hofler H, Walter GF, Denk H (1984) Immunohistochemistry of folliculostellate cells in normal human adenohypophyses and in pituitary adenomas. Acta Neuropathol (Berl) 65:35-40

20. Delfin L, Mete O, Asa SL (2021) Follicular cells in pituitary neuroendocrine tumors. Hum Pathol 114:1-8

21. Devnath S, Inoue K (2008) An insight to pituitary folliculo-stellate cells. J Neuroendocrinol 20:687-691

22. Denef C (2007) Paracrinicity: the story of thirty years of cellular pituitary crosstalk. J Neuroendocrinol 20:1-70

23. Vajtai I, Kappeler A, Sahli R (2007) Folliculo-stellate cells of "true dendritic" type are involved in the inflammatory microenvironment of tumor immunosurveillance of pituitary adenomas. Diagn Pathol 2(20):1-4

24. Farnoud M, Kujas M, Derome P, Racadot J, Peillon F, Li J (1994) Interactions between normal and tumoral tissues at the boundary of human anterior pituitary adenomas. An immunohistochemical study. Virchows Arch 424:75-82

25. Voit D, Saeger W, Lüdecke DK (1999) Folliculo-stellate cells in pituitary adenomas of patients with acromegaly. Pathol Res Pract 195:143-147

26. Osamura RY, Grossman A, Korbonits M, Kovacs K, Lopes MBS, Matsuno A, et al. Pituitary adenoma. WHO classif tumours endocr organs chapter 1 tumors Pituit Gland. Lyon: IARC Press; 2017. p. 14-8.

27. Villa C, Vasiljevic A, Jaffrain-Rea ML, Ansorge O, Asioli S, Barresi V et al (2019) A standardised diagnostic approach to pituitary neuroendocrine tumours (PitNETs): a European Pituitary Pathology Group (EPPG) proposal. Virchows Arch 475:687-692

28. Trouillas J, Roy P, Sturm N, Dantony E, Viennet G, Bonneville J-F et al (2013) A new prognostic clinicopathological classification of pituitary adenomas: a multicentric case-control study of 410 patients with 8 years post-operative follow-up. Acta Neuropathol (Berl) 126:123-135

29. Micko ASG, Wöhrer A, Wolfsberger S, Knosp E (2015) Invasion of the cavernous sinus space in pituitary adenomas: endoscopic verification and its correlation with an MRI-based classification. J Neurosurg 122:803-811

30. Ilie MD, Vasiljevic A, Louvet C, Jouanneau E, Raverot G (2020) Gonadotroph tumors show subtype differences that might have implications for therapy. Cancers 12:1012

31. Grzywa TM, Paskal W, Włodarski PK (2017) Intratumor and intertumor heterogeneity in melanoma. Transl Oncol 10:956-975

32. Liu J, Dang H, Wang XW (2018) The significance of intertumor and intratumor heterogeneity in liver cancer. Exp Mol Med 50:e416-e416

33. Hickman RA, Bruce JN, Otten M, Khandji AG, Flowers XE, Siegelin M et al (2021) Gonadotroph tumours with a low SF-1 labelling index are more likely to recur and are associated with enrichment of the PI3K-AKT pathway. Neuropathol Appl Neurobiol 47:415-427

34. Neou M, Villa C, Armignacco R, Jouinot A, Raffin-Sanson M-L, Septier A et al (2020) Pangenomic classification of pituitary neuroendocrine tumors. Cancer Cell 37:123-134.e5

35. Iwaki T, Kondo A, Takeshita I, Nakagaki H, Kitamura K, Tateishi J (1986) Proliferating potential of folliculo-stellate cells in human pituitary adenomas: immunohistochemical and electron microscopic analysis. Acta Neuropathol (Berl) 71:233-242

36. Kolnes AJ, Øystese KAB, Olarescu NC, Ringstad G, Berg-Johnsen J, CasarBorota O et al (2020) FSH levels are related to E-cadherin expression and subcellular location in nonfunctioning pituitary tumors. J Clin Endocrinol Metab 105:2587-2594

37. Friend KE, Chiou YK, Lopes MB, Laws ER, Hughes KM, Shupnik MA (1994) Estrogen receptor expression in human pituitary: correlation with immunohistochemistry in normal tissue, and immunohistochemistry and morphology in macroadenomas. J Clin Endocrinol Metab 78:1497-1504

38. Shupnik MA, Pitt LK, Soh AY, Anderson A, Lopes MB, Laws ER (1998) Selective expression of estrogen receptor $a$ and $\beta$ isoforms in human pituitary tumors ${ }^{1}$. J Clin Endocrinol Metab 83:3965-3972
39. Shang Y, Hu X, DiRenzo J, Lazar MA, Brown M (2000) Cofactor dynamics and sufficiency in estrogen receptor-regulated transcription. Cell 103:843-852

40. Renner U, Gloddek J, Pereda MP, Arzt E, Stalla GK (1998) Regulation and role of intrapituitary IL-6 production by folliculostellate cells. Domest Anim Endocrinol 15:353-362

41. Ying S-Y, Becker A, Baird A, Ling N, Ueno N, Esch F et al (1986) Type beta transforming growth factor (TGF- $\beta$ ) is a potent stimulator of the basal secretion of follicle stimulating hormone (FSH) in a pituitary monolayer system. Biochem Biophys Res Commun 135:950-956

42. Ueta Y, Levy A, Chowdrey HS, Lightman SL (1995) S?100 antigen-positive folliculostellate cells are not the source of IL-6 gene expression in human pituitary adenomas. J Neuroendocrinol 7:467-474

43. Sapochnik M, Haedo MR, Fuertes M, Ajler P, Carrizo G, Cervio A et al (2017) Autocrine IL-6 mediates pituitary tumor senescence. Oncotarget 8:4690-4702

44. Bilezikjian LM, Justice NJ, Blackler AN, Wiater E, Vale WW (2012) Cell-type specific modulation of pituitary cells by activin, inhibin and follistatin. Mo Cell Endocrinol 359:43-52

45. Pavlović M, Jovanović I, Ugrenović S, Vasović L, Krstić M, Bakić M et al (2013) Morphometric analysis of the human anterior pituitary's folliculostellate cells during the aging process. Ann Anat Anat Anz 195:231-237

46. Čukuranović Kokoris J, Jovanović I, Pantović V, Krstić M, Stanojković M, Milošević V et al (2017) Morphometric analysis of the folliculostellate cells and luteinizing hormone gonadotropic cells of the anterior pituitary of the men during the aging process. Tissue Cell 49:78-85

47. Fauquier T, Guerineau NC, McKinney RA, Bauer K, Mollard P (2001) Folliculostellate cell network: a route for long-distance communication in the anterior pituitary. Proc Natl Acad Sci 98:8891-8896

48. Hodson DJ, Legros C, Desarménien MG, Guérineau NC (2015) Roles of connexins and pannexins in (neuro)endocrine physiology. Cell Mol Life Sci 72:2911-2928

\section{Publisher's Note}

Springer Nature remains neutral with regard to jurisdictional claims in published maps and institutional affiliations.

Ready to submit your research? Choose BMC and benefit from

- fast, convenient online submission

- thorough peer review by experienced researchers in your field

- rapid publication on acceptance

- support for research data, including large and complex data types

- gold Open Access which fosters wider collaboration and increased citations

- maximum visibility for your research: over $100 \mathrm{M}$ website views per year

At BMC, research is always in progress.

Learn more biomedcentral.com/submissions 